\title{
Juan P. Quinteros, espiritista. Disputas por los sentidos legítimos del arte de curar. Santa Fe, fines del siglo XIX
}

por

\author{
Paula Sedran ${ }^{1}$ \\ Adrián Carbonetti \\ José Ignacio Allevi ${ }^{3}$ \\ CONICET / ISHIR-CESOR \\ CONICET / CIECS / FHUC \\ CONICET / ISHIR-CESOR
}

\begin{abstract}
A fines del siglo XIX, se anunció en Argentina un proceso de medicalización que formó parte de la formación del Estado y de la modernización social. Sobre él, las realidades locales y regionales evidencian características distinguibles, aunque se destaca como rasgo común que la consolidación de la élite médica como corporación se dio a partir de la lucha con otros actores sociales que también se ocupaban de la salud de la población. El presente artículo analiza los argumentos esgrimidos por el sanador espiritista Juan Quinteros, frente a la persecución que sufrió a manos del Consejo de Higiene, con el fin de identificar qué características del espiritismo fueron las que Quinteros hizo visibles en la defensa de su subjetividad y de su práctica sanadora.
\end{abstract}

Palabras Clave: Santa Fe; historia social de la salud; espiritismo; siglo XIX.

Cómo citar este artículo / Citation: Sedran, Paula, Carbonetti, Adrián y Allevi, José Ignacio, "Juan P. Quinteros, espiritista. Disputas por los sentidos legítimos del arte de curar. Santa Fe, fines del siglo XIX”, Revista de Indias, LXXVIII/274 (Madrid, 2018): 819-843. https://doi.org/10.3989/revindias.2018.025.

\section{INTRODUCCIÓN}

A finales del siglo XIX, comenzó en Argentina un proceso de medicalización que formó parte tanto del largo y complejo proceso de formación del Estado como de la modernización social. Sobre él, las realidades locales y

\footnotetext{
1 sedranpaula@gmail.com, ORCID iD: https://orcid.org/0000-0002-0592-0397.

2 acarbonetti2001@yahoo.com.ar, ORCID iD: http://orcid.org/0000-0002-2093-2046.

3 joseignacio.allevi@gmail.com, ORCID iD: http://orcid.org/0000-0003-4819-1398.
} de uso y distribución Creative Commons Reconocimiento 4.0 Internacional (CC BY 4.0). 
regionales evidencian características distinguibles, entre las que puede destacarse como un rasgo común, empero, que la consolidación de la élite médica como corporación se dio a partir de la lucha con otros actores, que también se ocupaban de la salud y a quienes los médicos — de la mano del Estadofueron colocando por fuera de la norma social.

En la provincia de Santa Fe, la incipiente élite médica desarrolló asociaciones y otras formas de institucionalización en las que el vínculo entre el Estado en formación y el naciente entramado profesional anticiparon «muchos de los criterios de intervención sobre la sociedad que se harían evidentes con el despliegue ya pleno de la Cuestión Social a principios del siglo XX» ${ }^{4}$. En este sentido, los médicos denunciaron, persiguieron y procuraron regular a las personas que atendían enfermos por fuera de los requisitos que la corporación intentaba instalar. Si bien a este respecto el caso santafesino resta ser indagado, diversos trabajos han estudiado la persecución de la que fueron objeto aquellos que se salían de los ámbitos de la medicina en el territorio que comprendía la Argentina 5 .

El presente artículo analiza los argumentos esgrimidos por Juan Quinteros, un individuo que basaba su práctica sanadora en el espiritismo y el magnetismo animal, frente a la persecución que, según denunció, sufrió a manos del presidente del Consejo de Higiene de la Provincia. Mediante el estudio de este caso, los objetivos propuestos son, por un lado, identificar la mirada que tenían los «perseguidos» y los «beneficiarios» a propósito de las medidas (estructuradas en un par de opuesto permitido-prohibido dado por la definición de práctica legítima) que los médicos pretendían imponer sobre ellos. Por otro, se señalarán cuáles características del espiritismo fueron las que este sanador resaltó y eligió hacer visibles, al momento de defender su práctica de lo que consideró un mote insultante y degradante, a saber el de «curandero», con que los calificó el Consejo de Higiene.

En esta dirección, una hipótesis plausible sugiere que uno de los puntos más urticantes que supuso el espiritismo —y prácticas asociadas a él, como el magnetismo animal - frente a la medicina académica fue que, como ésta, el espiritismo constituyó un conjunto de saberes y de prácticas que pretendió sostenerse sobre principios de la ciencia moderna. De esta forma, la construcción de sentido hecha por los defensores y practicantes del espiritismo, chocó con la pretensión del discurso médico de ser el portavoz exclusivo del lenguaje de la ciencia. Es en este sentido que el caso de Quinteros se conecta con el problema del monopolio de la legitimidad de curar en dos aspectos

4 González Leandri, 2006: 40.

5 Fleitas, 2007. Faberman, 2005. Garcés, 2010. Carbonetti, 1997. 
clave. Por una parte, al practicar su disciplina, al relacionarse con vecinos de la ciudad para curarlos, al ser buscado por ellos para tratar enfermedades, Quinteros disputó —en la práctica, ya que no en su discurso, como veremosel monopolio del conocimiento legítimo. Además, al no cobrar por sus servicios o recibir por ellos lo que pudieran darle y plantear la práctica sanadora como caridad, puso en entredicho el intercambio rentado como única forma de vínculo entre sanadores y enfermos.

Por último, este episodio, al que accedimos mediante la lectura de la presentación legal hecha por el apoderado del sanador, permite explorar la mirada que otros actores tuvieron en la transformación de los consensos sociales sobre las prácticas legítimas de atención de la salud, ya que cuenta con avales escritos de más de veinte vecinos. En ellos, los atendidos por Quinteros esgrimen qué razones tienen para defender a este hombre en su honor y buena fe, pero también, para pedir que se le permita seguir con su práctica.

Ahora bien ¿en qué contexto se desenvolvieron tanto la práctica de Quinteros, como su persecución y su defensa?

\section{EL ARTE DE CURAR Y SU LEGITIMIDAD EN EL MARCO DE LA MODERNIZACIÓN DECIMONÓNICA}

En Argentina, hacia fines del siglo XIX se vivieron modernizaciones en el Estado, la economía, la cultura y la composición societal, que generaron transformaciones importantes en las relaciones sociales ${ }^{6}$. En este marco, y como parte del aumento de la injerencia del Estado en la vida social, las dificultades referidas a la salud de la población estuvieron entre las preocupaciones más acuciantes, especialmente en relación a cómo hacer frente a enfermedades epidémicas y endémicas, en su mayor parte contagiosas.

En este contexto, una élite médica que se profesionalizaba de forma lenta, a la vez que ganaba espacios de decisión en puestos públicos clave, peleó por monopolizar el cuidado de la salud. Estos intentos cristalizaron en la conformación del Departamento Nacional de Higiene y los consejos provinciales, instituciones que se dedicaron a higienizar los espacios urbanos deteriorados - según su diagnóstico - por la presencia de inmigrantes ultramarinos; a enfrentar las epidemias esporádicas (fiebre amarilla, cólera, sarampión, viruela, escarlatina, etc.); a evaluar diplomas de médicos extranjeros y a combatir a los individuos que se ocupaban del cuidado de la salud desde una perspectiva empírica.

${ }^{6}$ Bonaudo, 2007. Reguera, 2009. Ayrolo, 2010. Fradkin y Garavaglia, 2011. 
No obstante la ventaja relativa que ese vínculo con el Estado supuso para los médicos por sobre otros actores, tanto la medicina académica como las terapias populares o tradicionales cargaban con un grado importante de incertidumbre sobre la efectividad de sus terapias. En líneas generales, la legitimidad de las prácticas médicas no superaba a la de curanderos, sanadores, hipnotistas, espiritistas y parteras, entre otros. En este sentido, Bubello destaca que el proceso de hegemonización tuvo como partícipes centrales a las políticas de descalificación y de represión de ciertas prácticas «heterogéneas» ${ }^{7}$. La lucha por establecer un sentido hegemónico sobre quién debía (y podía) curar fue central y, dentro de esta pelea, existieron dos aristas reconocibles: por un lado, la definición de qué prácticas eran efectivas; por otro, de cuáles serían permitidas. De forma concurrente, estos dos factores $-\mathrm{y}$ su materialización en prácticas que fueron desde la publicidad hasta la persecución policial de sanadores, curanderos y espiritistas - contribuyeron a la construcción de la hegemonía del discurso médico.

A propósito de las relaciones conflictivas entre médicos y otros sanadores, la preponderancia de fuentes discontinuas y fragmentarias no impide reconocer que algunas tensiones fueron recurrentes y se agudizaron ya hacia el final del siglo XIX. En este sentido, aun con sus zonas fragmentarias, el debate ha sido ampliamente superado respecto de ciertas visiones que atribuyeron una efectividad desmedida a la letra de las normas que regulaban la praxis médica desde el siglo XVIII. Al igual que en otros países de Europa ${ }^{8}$ y América Latina $^{9}$, los vínculos entre médicos y otras formas de curar, en especial el espiritismo, arraigados con fuerza en la realidad social y sanitaria de las poblaciones, se han constituido en objeto de indagación histórica en los últimos años.

Para el caso argentino, los trabajos que analizan a quienes curaban fuera de la tradición académica se enfocaron, por lo general, en el curanderismo o el parterismo. Ejemplos de ello son los estudios sobre casos dados en las actuales provincias de Tucumán ${ }^{10}$, Jujuy ${ }^{11}$, Córdoba ${ }^{12}$, territorios nacionales ${ }^{13}$, y Buenos Aires ${ }^{14}$. Estos estudios, comprendidos en el campo de la historia

7 Bubello, 2010.

8 González de Pablo, 2006a. Graus, 2014. Edelman, 2006.

9 Sowell, 2002. Weber, 1999. Para un abordaje sobre los trabajos en Brasil ver Müller, 2009

10 Fabermann, 2005.

11 Fleitas, 2008.

12 Carbonetti, 1997.

13 Di Liscia, 2003.

14 Armus, 2007. Dahhur, 2013. 
social y cultural de la salud y la enfermedad ${ }^{15}$ afrontan dificultades documentales que, en buena medida, han marcado el ritmo de constitución de este subcampo historiográfico. Dichas limitaciones son compartidas por los estudios sociales del siglo XIX y pueden organizarse, aun en su diversidad, en dos tipos generales. Por una parte, se encuentra la escasez o discontinuidad documental; por otro, la particularidad de haber sido producidos en su gran mayoría por élites - médicas o no- ligadas a las esferas estatales. Es por ello que los avances historiográficos se han valido de enfoques interdisciplinarios en profundidad, especialmente antropológicos ${ }^{16}$ y sociológicos ${ }^{17}$, que estudian la medicina alternativa, popular o no académica en sociedades contemporáneas. Éstos contribuyeron a cuestionar la mirada etapista del conocimiento médico con que los primeros ensayos de la historia de la medicina inscribieron estas prácticas en el relato de la modernidad. Principalmente, han permitido resaltar el carácter conflictivo, discontinuo y relacional de la institucionalización de ciertas prácticas y sentidos ligados a la salud.

Por otra parte, los trabajos existentes reúnen dos condiciones que, en el estado actual de estos estudios y considerando las particularidades documentales señaladas, resultan de suma importancia. En primer término, ponen en relieve los rasgos propios de las regiones estudiadas, y los consideran en tensión con las miradas y explicaciones generales. En segundo lugar, rescatan el estudio del «acontecimiento» como parte constitutiva de la trama social, lo cual permite una lectura en profundidad de fuentes discontinuas.

Dichos estudios se interrogan sobre objetos diversos, desde el grado de efectividad que el ejercicio de la autoridad del Estado tuvo con respecto a las prácticas de medicina no diplomada, popular o curanderismo, hasta la específica forma en que la aparición de los Consejos de Higiene — ligada a coyunturas sanitarias y políticas- ${ }^{18}$ y la construcción de los curanderos como sus primeros enemigos indica el lugar que la salud pública ocupó en los ciclos de atención del Estado en formación ${ }^{19}$. Estos interrogantes están vinculados a los procesos de conformación de la profesión médica dotada de legitimidad académica, pero principalmente social a escala local y regional. Así, los médicos «oficiales» fueron logrando que sus propuestas ganaran peso en las

\footnotetext{
15 Di Liscia, 2008: 15-47. Armus, 2007.

16 Nebreda, 1995.

17 Mallimaci y Giménez Béliveau, 2007.

18 González Leandri, 2004. Pascual, 2015. Prieto, 1997.

19 Rodríguez, Carbonetti y Andreatta, 2013.
} 
políticas públicas ${ }^{20}$, posición desde la cual abogaron por el cumplimiento de las condiciones que la medicina académica debía reunir.

Lo antedicho pone de manifiesto que los estudios existentes sobre curanderos, sanadores y la medicina popular no arrojan aún una visión general del tema, como así tampoco sobre la problemática específica de la tensión entre éstos y los médicos.

\section{LA CIENCIA Y LA MORAL DEL ESPIRITISMO EN LA LUCHA POR LA LEGITIMIDAD}

El espiritismo se componía de un conjunto de observaciones y exploraciones cuyo coincidía con los intereses de algunas ramas de la ciencia y, además, era practicado por científicos de renombre mundial. Ello reforzó su carácter de práctica híbrida o fronteriza, en que el «cruce de frontera» ${ }^{21}$, se comprobaba no sólo en los interrogantes que guiaban las experiencias sino también en su construcción discursiva. El rescate del empirismo como método (en las anotaciones minuciosas, en la forma experimental de las sesiones, en la comparación de resultados, entre otros rasgos), acercaron el espiritismo a la práctica científica ya validada socialmente. Esto provocó, a su vez, que destacados intelectuales, científicos y escritores se hallaran dispuestos a poner en juego sus reputaciones y abrazaran el movimiento, o lo incluyeran en sus visiones del mundo ${ }^{22}$.

Esa cercanía comportaba, desde el discurso médico en proceso de hegemonizar el campo de la salud, un peligro de contaminación simbólica, ya que el espiritismo reclamaba para sí parte de un terreno que la medicina pretendía monopolizar. Ello representaba un problema ya que, si la medicina hacía descansar su legitimidad sobre el principio de verdad científico, ¿en qué clave impugnaría a un saber que decía tener los mismos orígenes, fundamentos y lógica cognoscente? En este punto, la relación del espiritismo con el magnetismo fue uno de sus aspectos más debatidos, ya que este último fue construido sobre principios materialistas y biologicistas ${ }^{23}$. Por ello, esta reacción del discurso médico ante el peligro de tener que compartir la fuente de su legitimidad, bien puede ser una primera hipótesis para acercarnos a este caso de persecución. Entre otros factores, porque el espiritismo en Argentina, amén

\footnotetext{
20 Carbonetti, 1997. González Leandri, 2006.

21 Quereilhac, 2010: 86.

22 Bonet Safont, 2014.

23 Montiel, 2006: 15.
} 
de sus variaciones, reivindicó un carácter racionalista ${ }^{24}$ y se vinculó estrechamente a la práctica del magnetismo que, a lo largo del siglo XIX, había pugnado por establecerse como parte del campo de la medicina europea.

El hilo conductor que existió entre espiritismo y magnetismo se tendió tempranamente. Como observa Edelman «la medicina espiritista se apoya esencialmente en las prácticas procedentes del magnetismo animal y sobre la convicción en que existe un fluido magnético» ${ }^{25}$. Desde esta perspectiva, la enfermedad procedería de diversas alteraciones de este flujo y la terapéutica debía estar en relación a la modificación del fluido magnético, equilibrando el mismo, a individuos magnetizados ${ }^{26}$. Los individuos utilizados en las terapias, para vincularlos a la persona enferma, con lo cual restituían el balance de los flujos magnéticos de ésta, eran en su mayoría mujeres.

Existía una característica de las terapias magnéticas que, por sobre otras, podía significar una amenaza para el saber médico: según se la describe en los casos documentados, la relación entre el enfermo y la persona que sana se caracterizaba por la empatía y la comunión, antes que por la asimetría que caracterizaba a la de autoridad y paciente (Montiel, 2006: 17 y 21). Ello, como se verá, también constituyó un punto importante de lo que Quinteros llamó $\mathrm{su}$ «misión caritativa».

El vínculo entre el magnetismo y el espiritismo se dio, primordialmente, por vía de los casos estudiados en los que las pacientes veían espíritus, con los cuales interactuaban y que podían ser presencias beneficiosas o dañinas. El reconocimiento de la existencia de espíritus que rodeaban al cuerpo físico del ser humano se proponía como la develación de los misterios opacos del universo, continuación de la develación de la opacidad del cuerpo humano que Mesmer había comenzado. El trance hipnótico con el que el magnetizador curaba, tenía su correlato en aquel del médium espiritista, al contactar a las presencias del más allá, que no eran sino un «fluido muy sutil, el fluido nervioso» del alma que se desprendía del cuerpo al momento de la muerte. De hecho magnetizador, médium y espiritista se utilizaban frecuentemente como sinónimos ${ }^{27}$.

En Argentina como en Latinoamérica, el nuevo cruce que el espiritismo proponía entre ciencia y alma fue rechazado con la misma vehemencia por los guardianes consagrados de ambas dimensiones: la corporación médica y la Iglesia. Como resumió un famoso obispo mexicano en 1869, el espiritismo

\footnotetext{
24 Bubello, 2010.

25 Edelman, 2006: 43.

26 González de Pablo, 2006b: 281.

27 Carrilllo, 1869: 11.
} 
integraba el conjunto de «aquellas prácticas vendidas por sus propagandistas como las operaciones de una ciencia [que realmente eran] el absurdo, la necedad y la ridiculez hermanadas con el ciego fanatismo y la ignorante superstición como los más eficaces auxiliares de la irreligión, del grosero materialismo o de un espiritualismo absurdamente comprendido y explicado» ${ }^{28}$. Los vínculos estrechos entre fe y ciencia, que los médicos achacaban a curanderos y sanadores, era también utilizada por los saberes ortodoxos. En este caso, el obispo, para su alegato contra la irreligión, cita como autoridad al «facultativo en física y medicina [D. Federico Pedrera] que vino en nuestra ayuda ${ }^{29}$.

Finalmente, importa señalar que los años finales del siglo comprendieron un período de transición en relación a cómo el Estado reprimió el ejercicio ilegal de la medicina (durante el cual se apuntó a prácticas esotéricas y mágicas cada vez más diversas, de raigambre tradicional o moderna) ${ }^{30}$. Bubello destaca que se enjuició y penó el ejercicio de estas terapias a la vez que se lo autorizó en ciertas circunstancias y es en dicho contexto, de una prohibición y clasificación que supusieron tanto definiciones científicas como la ponderación de recursos y circunstancias, que los ataques al espiritismo se pronunciaron. El caso de Quinteros forma parte de ese embate y, puede pensarse también, participa del tono general que tomaron las respuestas de los espiritistas. Dice el autor que «desde 1890, los espiritistas elaboraron una táctica que luego mantuvieron a lo largo de todo el siglo XX: salieron a diferenciarse de los curanderos» ${ }^{31}$.

Específicamente en relación a nuestro objeto, no sobran los trabajos que analicen las estrategias de pervivencia y defensa de curanderos y sanadores frente a las instituciones médicas en el período ${ }^{32}$. Algunos casos, empero, resultan ejemplares de una serie de procesos subyacentes a la figuración pública de estos personajes. Steven Palmer analizó con agudeza el caso de Carlos Carballo Romero - conocido como el Profesor Carbell - para la década de $1930^{33}$. En efecto, Carbell, reunía una serie de saberes que vinculaban el plano espiritual y el médico, y al momento de ser denunciado por la Policía de Salubridad, presentó su caso no sólo con un número importante de testimonios a su favor sino que realizó un uso estratégico de una miríada de

\footnotetext{
28 Ibidem: 8.

29 Ibidem: 3.

30 Bubello, 2010: 59.

31 Ibidem: 110.

32 Dahhur, 2013. Fleitas, 2008. Di Liscia, 2003.

33 Palmer, 2002.
} 
medios escritos ${ }^{34}$. En su análisis, Palmer expone que el éxito de Carbell (y la persecución de la que fue objeto por los médicos diplomados) era, en realidad, el espejo de un proceso sobre el eclecticismo médico que se presentaba como una nueva dimensión de la medicina popular. Al mismo tiempo, afirma que se dio en el marco de un particular proceso de imbricación de los mundos privados y públicos con la política, a la luz del fenómeno que el autor abordó como «populismo médico» ${ }^{35}$.

Mauro Vallejo, por su parte, historiza el desarrollo del hipnotismo en la ciudad de Buenos Aires. Para ello, ofrece el estudio de caso sobre Alberto Díaz de Quintana, un médico español que emigra, abre su propio consultorio y es luego acusado por el Departamento Nacional de Higiene en 1891 por no prestarse a revalidar su título. La relevancia de este aparente «caso singular», demuestra Vallejo, radica en que la presencia de Díaz de Quintana era todo menos una excepción, y que la denuncia en su contra se enmarcaba tanto en los cambios de regulaciones al interior de la agencia estatal como por la crisis de 1890 y sus repercusiones ${ }^{36}$. El recurso del autor al rastrear la defensa del médico español en la prensa pone de manifiesto no sólo la posibilidad existente de facto para disputar una serie de sentidos en torno a la salud y a sus prestadores en ámbitos públicos, sino también la debilidad misma de las instituciones y visiones oficiales al respecto.

En este sentido, el documento principal de nuestro análisis - la demanda que entabla el espiritista Juan Quinteros al presidente del Consejo de Higiene- se inserta en este conjunto renovado de discusiones, habilitando un acercamiento no sólo en la mirada de un espiritista sobre su propia práctica y sobre la medicina sino que también arroja luz sobre algunos de los medios que los médicos utilizaron para combatir a estos sujetos. Como veremos, la cuestión de la legitimidad de unos y otros atraviesa la extensa exposición y, en este sentido, el espiritismo - por su naturaleza y los actores que lo llevaron adelante- permite explorar, poner en cuestión, la dicotomía con que se han interpretado las relaciones entre la ciencia médica y los saberes empíri$\cos ^{37}$. Con esos interrogantes en mente, los apartados subsiguientes recorren distintas aristas del enfrentamiento. Luego de una contextualización sobre la Santa Fe de finales de siglo, se analizan los argumentos que Quinteros esgrimió no sólo contra las penas que le fueron aplicadas sino a favor del espiri-

\footnotetext{
34 Molina y Palmer, 1996.

35 Palmer, 2002.

36 Vallejo, 2015: 53-84.

37 Quereilhac, 2010: 81.
} 
tismo, que reivindicó científica y moralmente y se consideran en función de estos argumentos, algunos enunciados presentes en los avales de los vecinos.

\section{CONTEXTO PROVINCIAL y ESPIRITISMO, EN EL ÚlTimo CUARTO DE SIGLO}

La provincia de Santa Fe ocupa el centro de la zona más productiva del modelo agroexportador que se consolidó en la Argentina durante el período. Sus tierras fértiles de llanura permitieron la producción (ganadera, a la cual se sumó luego la agrícola), que hizo despegar las exportaciones y provocó la implementación de una serie de políticas para sostener esa vía de crecimiento económico que afectaron notoriamente la dinámica de la vida social. Entre ellas, se destacó el fomento estatal de la inmigración europea, con el fin de proveer de brazos que trabajasen la tierra e importasen una cultura acorde a la civilización que se proyectaba. El aumento y diversificación de la población, así como el crecimiento de los centros urbanos, trajeron consigo problemas de la salud que, si no eran nuevos, sí aparecían con mayor impacto por su escala y concitaron la atención del Estado (que estaba construyendo sus instituciones y sus formas de intervención).

Por ejemplo, sobre la ciudad de Santa Fe, capital de la provincia, puede señalarse, de acuerdo al primer y al segundo censos nacionales, que en ella vivían, hacia $1869,10.670$ personas y en $1895,22.244$. De esta manera, en 1886, año en que se registra la demanda sentada contra Quinteros que analizamos, la ciudad contaba con una población que había aumentado notablemente, especialmente de la mano de la inmigración ultramarina ${ }^{38}$, lo cual hizo necesarios mayores recursos para la atención de la salud de sus habitantes.

En dicho contexto, los médicos fueron agentes activos en la construcción e implementación de dichas herramientas de intervención estatal. Desde su participación en la elaboración de ordenanzas municipales y prescripción de medidas para enfrentar brotes epidémicos, hasta la conformación de sus propios órganos corporativos dentro del Estado (como los Consejos de Higiene), los médicos formaron parte de la institucionalización de específicas relaciones de dominación en lo que se refiere a las formas de nominar, administrar e intervenir sobre la salud pública. Ahora bien, estas propuestas y negociaciones no se hicieron en el vacío, ni estuvieron libres de condicionamientos o contradicciones. La provincia presentaba ciertos rasgos - esquemáticamente: políticos y económicos - que dieron el marco al avance del Estado y de los médicos sobre ámbitos de la vida social sobre los que reclamaban injerencia.

38 Bonaudo, 2007. Lobato, 2000. 
En lo que respecta a la dimensión política, hacia fines de la década de 1870, Santa Fe dejaba atrás, como la mayoría del país, la vía armada para dirimir la competencia política, cuya forma más destacada fueron los alzamientos o «revoluciones ${ }^{39}$. Una mayor consolidación de la estructura del poder político provincial, en manos de una facción del autonomismo oligárquico que comandaba el país, se tradujo, asimismo, en el afianzamiento de una estructura político-administrativa verticalista. Este rasgo, en función de nuestro objeto, resalta el hecho de que instituciones clave en el control de los asuntos públicos (policía, justicia de paz, así como los organismos corporativos mixtos creados en esos años, como el Consejo de Higiene) presentaron una articulación inextricable con el poder político provincial. En consecuencia, su conformación y pervivencia también dependieron del devenir de los enfrentamientos facciosos. Otro factor relevante en la lucha por instalar un discurso hegemónico sobre la salud fueron las limitaciones materiales del Estado en formación, en especial porque socavaban su capacidad de dar cumplimiento a sus propias disposiciones, como el caso del «ejercicio ilegal de la medicina» en colonias y pueblos alejados o en la campaña. En numerosos documentos, se solicita al gobierno provincial que autorice a ciertas personas a atender la salud de los pobladores. Son reiterados los pedidos interpuestos por colonos, otros pobladores de la campaña y autoridades locales al Estado provincial y, luego, al Consejo de Higiene, para que provean agentes médicos que puedan desempeñar esa labor en pequeños poblados, «despojados de toda atención».

Con respecto a quienes se ocupaban efectivamente de las dolencias y enfermedades de esta población, el censo nacional reconoce 26 curanderos cada cien mil habitantes en la provincia de Santa Fe, dato que adquiere relevancia si se considera que, en el mismo año, había 0,40 médicos ${ }^{40}$. Además de estos factores, resta establecer las divergencias de la presencia numérica de cada uno de ellos en ciudades, colonias y campaña, disposición que fue de la mano con el mayor interés de los médicos por la definición y el control del mercado de trabajo en las ciudades y en las colonias más pujantes, ya desde la década de 1860 .

En tal sentido, la «competencia» entre médicos y otros sujetos que curaban, evidenciada en el documento analizado, se recorta en un escenario condicionado tanto por el grado de estructuración y modernización institucional y de las dinámicas socioeconómicas, así como por los procesos de consolidación de las profesiones diplomadas. Como se verá, este es también uno de los argumentos esgrimidos en la explicación que Quinteros da de su labor. En

\footnotetext{
39 Álvarez, 1910. Gallo y Wilde, 1980.

40 Rodríguez, Carbonetti y Andreatta, 2013: 92.
} 
ella, el componente filantrópico es central (y se materializa cuando explica que brinda sus servicios de forma gratuita). Esta práctica supuso una competencia real a uno de los puntos que el discurso médico buscaba imponer como parte de la profesionalización, a saber, la práctica remunerada como única forma legítima de vínculo entre enfermos y sanadores.

La discusión pública sobre la modernización institucional e infraestructural durante la última década del siglo se entretejió con esas cuestiones - las competencias, jurisdicciones y funciones de los médicos y del Estado-, principalmente en la forma de reclamos, reflexiones y denuncias. Se delimitó así un conjunto de asuntos urgentes de abordarse en función de los cambios acelerados que atravesaba la vida en la ciudad. Entre ellos, se encontró la epidemia de cólera de 1886-87, que reveló de forma cruenta la insuficiencia de médicos, de tratamientos y de infraestructura para afrontarla y puso al descubierto una serie de intereses más específicamente delimitables. Por caso, cómo los médicos influyentes ligados al Estado nominaron, clasificaron y se opusieron a prácticas como las del espiritismo de una forma distinta a como lo hicieron con el curanderismo u otros sanadores. En su consideración, como veremos, esto juega un rol central, toda vez que la estrategia central parece ser la deslegitimación del sanador, precisamente rotulándolo de curandero y estafador. Por su parte, Juan Quinteros, que se encontraba en la ciudad hacía ya dos años cuando la epidemia se declaró y contaba con un apoyo amplio entre sectores populares y de élite, litigó esta mirada descalificante. Defendió el método magnético y el espiritismo que practicaba diciendo dos cosas: una, que no se trataba de medicina $y$, por tanto, era inconducente acusarlo de ejercicio ilegal; segundo, que su práctica no perseguía el lucro.

El conflicto en el que se vio envuelto se desató cuando el pico epidémico había comenzado a declinar y la vida en la ciudad (y en la administración del gobierno) retomaba su devenir habitual, además de haber ocurrido en el año en que se crea por ley el Consejo de Higiene de la Provincia de Santa Fe.

\section{UNA DISPUTA POR EL SENTIDO: REPRESENTACIONES SOBRE ESPIRITISMO Y DERECHOS EN LA DEMANDA DE JUAN QUINTEROS}

«El H. Consejo puede obstinarse, contra Quinteros, calificándole de impostor, y a su procedimiento curativo de ridículo, pero nunca podrá negar la veracidad de los hechos constatados en los certificados adjuntos» ${ }^{41}$.

41 Atanacio Páez en representación de Don Juan P. Quinteros contra el Consejo de Higiene, 26 de octubre de 1887, Archivo General de la Provincia de Santa Fe (en adelante, 
En la demanda que presenta al Poder Ejecutivo, en 1887, Atanasio Páez, representante legal de Quinteros, se explaya sobre las razones por las que su defendido ha sido injustamente perseguido, multado y hasta encarcelado por órdenes del Consejo de Higiene. Todas las consideraciones de la efectividad, la inocuidad y la gratuidad del tratamiento de Quinteros se sostienen sobre unos 20 testimonios escritos y más de 300 firmas recolectadas por pacientes satisfechos y agradecidos, muchos de ellos personas de renombre en la ciudad.

La composición de los testimonios merece algunas puntualizaciones dado que, si bien el escrito central de la presentación se sostiene sobre argumentos científicos (el renombre y aceptación del espiritismo y el magnetismo en los círculos intelectuales y científicos europeos) y legales (que Quinteros no quebraba ninguna ley y que por tanto las penas impuestas sobre él eran vejatorias de derechos constitucionales), el documento comienza con una afirmación tan fuerte como la citada. Esta hace recaer la legitimidad de la presentación en el carácter irrefutable de estos testimonios.

Es de suponerse que la apuesta a la fuerza de estos avales recaía en quiénes eran algunos de los firmantes. Entre ellos, pueden nombrarse al ex primer oficial de policía e integrante de una familia destacada, Acisclo Niklison, y otros militares como el Coronel Olmedo, la esposa del vicecónsul español, Jacinta Torres. Los restantes incluyeron individuos como Manuel Otaño, propietario de una fábrica de cal, varias mujeres (cuyas afecciones son principalmente estomacales), así como individuos pobres, como el caso de Acisclo Cepeda, que, en una carta de agradecimiento que Páez adjunta a la presentación, dice que «le remito un par de gallinas para que se sirva de ellas a mi nombre, pues debido a Ud. me siento con fuerzas para ganarme el pan de mi existencia» ${ }^{42}$.

El documento puntualiza un aspecto particular, a saber, que detrás del plano regulador donde se desplegó la denuncia se podía reconocer un particular encono contra Quinteros de parte del presidente del Consejo de Higiene. Este conspicuo personaje de la élite social y política santafesina solicitó para Quinteros una pena mayor a las multas que la normativa estipulaba para el «ejercicio ilegal de la medicina», delito del que se lo acusó. Pidió incluso su

AGPSF), Ministerio de Gobierno, Agricultura, Culto e Instrucción Pública, Sección Gobierno y Culto, expediente núm. 30, folio 31. El expediente consta de 53 fojas, que no se encuentran numeradas, con excepción de las 22 primeras, que corresponden a testimonios de vecinos de la ciudad, que Atanasio Páez incorpora a su escrito. El número de folio corresponde a una numeración consecutiva realizada por los autores a fin de ordenar las citas textuales.

42 Atanacio Páez en representación de Don Juan P. Quinteros contra el Consejo de Higiene, 26 de octubre de 1887, AGPSF, Ministerio de Gobierno, Agricultura, Culto e Instrucción Pública, Sección Gobierno y Culto, expediente núm. 30, testimonio núm.17. 
encarcelamiento porque, según argumentaba, la conducta de este espiritista no sólo infringía las normas en salud sino que demostraba una total irreverencia y descuido hacia las autoridades —en ese caso, él mismo. El escrito de Páez se estructura como una abierta denuncia de estos atropellos ilegales e ilegítimos, a la vez que como una defensa enérgica de la práctica sanadora de Quinteros. En él, se solicita que queden sin efecto las multas ya abonadas (la última de las cuales, de la onerosa suma de 100 pesos, lo había dejado en la ruina) y se le restituya su dinero. Además, «censura la conducta» del Consejo y pide al juez que «ponga coto y una merecida represión a los miembros que componen aquella Corporación, que sin miratorias, basados tan sólo en los cuentos de barrio» ${ }^{43}$, hostigaban a su instituyente.

Aunque este artículo no indaga en la arista estrictamente política de este enfrentamiento, es de suponer que la enemistad tenía una naturaleza más profunda que sólo la de cuentos de barrio. Al relevar los periódicos locales, el episodio que se denuncia no aparece como tal. Sin embargo, sí existen (en un diario afín a la facción oficialista del autonomismo en el que también se hallan numerosas notas laudatorias a la persona de Cándido Pujato, reciente ex gobernador) notas mencionando que la facción opositora se apoyaba en un «charlatán que cura con agua», en el que se les acusaba de buscar consejo político, en un gesto que buscaba insultar la racionalidad y la solvencia de sus adversarios internos ${ }^{44}$.

En ese aspecto, la presentación supone no sólo una declaración de principios sino una defensa encendida y altiva de lo que considera derechos inalienables: la potestad de ejercer una profesión y defender unas ideas libremente.

Para justificar el reclamo, Páez anuncia que demostrará tres puntos: que Quinteros basaba sus sanaciones en el espiritismo; que, por tanto, no practicaba la medicina; y que puesto que era una misión de caridad, no cobraba por sus servicios. Al estar estos hechos probados, dice que la acusación de ejercicio ilegal de la medicina es infundada ya que las curaciones de Quinteros «no se basan en el sistema Alopático, Homeopático o Quirúrgico (...) no se vale nunca de drogas, específicos, aguas minerales ó artificiales ni receta medicamentos de los que espenden las Boticas ni farmacias $\rangle^{45}$, ella escondería intenciones inconfesables y mezquinas del presidente del Consejo.

43 Atanacio Páez en representación de Don Juan P. Quinteros contra el Consejo de Higiene, 26 de octubre de 1887, AGPSF, Ministerio de Gobierno, Agricultura, Culto e Instrucción Pública, Sección Gobierno y Culto, expediente núm. 30, folio 32.

44 Periódico La Revolución, Santa Fe, 14 de abril de 1886, AGPSF.

45 Idem. 
Esas afirmaciones conducían hacia un punto ulterior, que tiñe todo el documento y le da una impronta de justa indignación: si era tan claro que Quinteros no pretendía practicar la medicina, ¿cuál era la razón de las acusaciones recibidas? Parte de este interrogante se responde cuando Páez denuncia, también, que el honor de Quinteros ha sido mancillado cuando se lo denomina «curandero». Ello lo ofendía profundamente y llevó a su procurador a puntualizar por qué se trataba de una calumnia.

En primera instancia, queda claro por qué no era Quinteros un curandero: no lucraba y no utilizaba "procedimientos desconocidos o misteriosos» que pudiesen poner en riesgo la salud de las personas que atendía. Ahora bien, el mote de curandero iba más allá de las prácticas efectivas. Si resultaba tan ofensivo, es porque suponía la pertenencia a un grupo bajo, moralmente reprobable, ignorante y que lucraba con la desesperación del pueblo. Llamarlo curandero es incluirlo en el grupo de «tan bajas condiciones sociales en que suelen encontrarse los holgazanes que no teniendo industria, arte ni oficio lícito, inventan artimañas para procurarse un sustento o bienestar a costa de los incautos» ${ }^{46}$. Su defendido no formaba parte de «esa multitud de curanderos, algunos que sin título académico, y sin las nociones elementales de la medicina pretendían hacer creer al vulgo el hecho de practicar curaciones milagrosas por medios extraños y misteriosos y ayudados por una ciencia oculta, cuando todos sabemos que no hacen sino valerse por medios astutos $\mathrm{y}$ artificiales vendiendo drogas y hungüentos [sic] $\rangle^{47}$.

Esta descripción no sólo diferenciaba a Quinteros de quienes lucraban mediante la estafa, sino que también legitimaba su accionar desde la caridad y la gratuidad (punto incómodo para la pretensión médica de establecer el cuidado rentado de la salud).

Ahora bien, existen otros aspectos en que el documento presenta guiños desafiantes. Con una sutileza que se va perdiendo en el desarrollo del texto y con la repetición de los argumentos, Páez desliza dos ideas que cuestionan las bases del monopolio tal como los médicos pretendían construirlo. Afirma, por un lado, que el conocimiento médico no es infalible ni siempre la mejor opción, replicando en la demanda las afirmaciones de los testimonios adjuntos en las que los vecinos decían recurrir a Quinteros sólo ante el fracaso de los

46 Guillermo Ovalle se presenta en queja contra los curanderos de Helvecia, 8 de octubre de 1894, F.5, AGPSF, Ministerio de Gobierno, Agricultura, Culto e Instrucción Pública, Sección Gobierno y Culto, expediente núm. 6, folio 5.

47 Atanacio Páez en representación de Don Juan P. Quinteros contra el Consejo de Higiene, 26 de octubre de 1887, AGPSF, Ministerio de Gobierno, Agricultura, Culto e Instrucción Pública, Sección Gobierno y Culto, expediente núm. 30, folio 36. 
facultativos. Sugiere, por otro lado, que los individuos que componen el cuerpo médico local, quizás no sean lo doctos que dicen ser y los acusa de ignorar los adelantos de la ciencia: «El sistema especial usado por Quinteros desconocido tal vez por el $\mathrm{H}$. Consejo de Higiene y especialmente por su actual presidente está aceptado por una gran parte del pueblo regularmente ilustrado y varias Naciones civilizadas del viejo continente. (...) Ignoro, Exmo. Señor, si el Consejo está interiorizado de los fenómenos hipnóticos del Espiritismo» ${ }^{48}$.

En cuanto a sus fundamentos, el espiritismo — así como la fe en que el agua común podía curar - suponía una mirada sobre la salud y el cuerpo humano que excede las nociones biologicistas que la medicalización impulsaba $^{49}$. De la mano de estas nociones de salud y su administración que Páez propone, vendrán consideraciones sobre las bases de la legitimidad del arte de curar que abiertamente discuten con aquella que los médicos buscaban imponer.

Se destaca que la misión caritativa fue central en el espiritismo, la cual demostró «la pureza de sus intenciones como sistema filosófico y la claridad de sus leyes y principios como ciencia natural ${ }^{50}$. Ello se ve reflejado en las dos estrategias discursivas que estructuran la validación de esta «ciencia» en la demanda. Por un lado, se subraya su misión caritativa y se afirma que es el deber de los espiritistas «aliviar a los dolientes», principalmente porque «el poder que anima las curaciones» es «la inspiración divina», que no puede tener otro fin que hacer el bien desinteresadamente.

A este respecto, las notas de aval son clave. Más allá que la redacción casi idéntica, como una fórmula, de la mayoría de ellas, inspire a pensar que Páez incidió mucho en su confección, eso no va en desmedro de la voluntad de cada uno de esos individuos de hacer un alegato a favor de Quinteros. Los testimonios comparten el formato siguiente, ejemplificado en el caso del «Coronel Olmedo»:

El que suscribe, vecino de esta ciudad domiciliado en la calle denominada 1 de Mayo, declara lo siguiente: Que vez pasada encontrándose enfermo el joven Anacleto Sabala, en casa de sus padres Don Ramón Sabala y Doña Isidora de

48 Atanacio Páez en representación de Don Juan P. Quinteros contra el Consejo de Higiene, 26 de octubre de 1887, AGPSF, Ministerio de Gobierno, Agricultura, Culto e Instrucción Pública, Sección Gobierno y Culto, expediente núm. 30, folio 39.

49 Armus, 2007.

50 Atanacio Páez en representación de Don Juan P. Quinteros contra el Consejo de Higiene, 26 de octubre de 1887, AGPSF, Ministerio de Gobierno, Agricultura, Culto e Instrucción Pública, Sección Gobierno y Culto, expediente núm. 30, folio 37. 
Sabala, domiciliados en la calle General Urquiza, de desorganización mental grave, y a pedido del que firma, se solicitaron los servicios de Don Juan P. Quinteros, quien con sólo administrar en pequeñas dosis el agua natural obtuvo una ezelente curación al enfermo, el que hoy se encuentra gozando de completa salud. Nunca pasó cuenta alguna por sus honorarios ${ }^{51}$.

Además, agrega que: «el Dr. Gollán [ex presidente del Consejo de Higiene de la Provincia] fue quien lo ezaminó primero y dijo que era enfermedad moral y que sólo había el medio para curarlo, sacarlo al campo, y por no poder hacerlo, yo indiqué los servicios del Sr. Quinteros» ${ }^{52}$.

Los elementos que este escrito comparte con los restantes es que destaca que Quinteros fue buscado (más allá de dar cuenta de una red de relaciones y confianza que era la que llevaba los pacientes a determinados sanadores). Luego, que no utilizó drogas ni medicinas de botica en su tratamiento. Finalmente, que no exigió ningún pago por su labor. Además, se puntualiza un elemento que también aparece en algunos otros casos, y que se constituye en un argumento en la misma defensa de Páez: Olmedo dice que sólo recurrieron a Quinteros cuando la medicina diplomada (corporizada en uno de los médicos más prestigiosos de la ciudad) falló en curar al enfermo, noción que se refuerza en los restantes testimonios.

En ocasiones, ello podía significar más de un intento, como el que describe Desideria Bracamonte, que declara que «he padecido durante catorce años un terrible flujo de vientre, para cuyo mal he sido asistida muchos años por los doctores Fontán, Molinas, Pujato y el doctor Alarcón que me prestó los auxilios de su ciencia más de seis meses sin haber obtenido alivio alguno de la dolencia por más tratamientos y medicamentos que me ha prohijado ${ }^{53}$. En los testimonios se destaca, asimismo, la variedad de dolencias que Quinteros curó, que incluyó «desorganización mental grave», «sarampión», «pulmonía», «flujo de vientre», entre otras.

Por otro lado, como «ciencia natural» se lo sitúa del lado del progreso y la civilización, frente a sus detractores, que serían «los retrógrados y los orgullosos». El espiritismo, argumenta Paéz, sería una «ciencia nueva pero

51 Subrayado en el original.

52 Atanacio Páez en representación de Don Juan P. Quinteros contra el Consejo de Higiene, 26 de octubre de 1887, AGPSF, Ministerio de Gobierno, Agricultura, Culto e Instrucción Pública, Sección Gobierno y Culto, expediente núm. 30, S/F, testimonio núm. 2. El subrayado pertenece al original.

53 Atanacio Páez en representación de Don Juan P. Quinteros contra el Consejo de Higiene, 26 de octubre de 1887, AGPSF, Ministerio de Gobierno, Agricultura, Culto e Instrucción Pública, Sección Gobierno y Culto, expediente núm. 30, S/F, testimonio núm. 11. 
positiva, que no está basada en lo sobrenatural y en lo misterioso [pero que] está pasando por un período cruento de la censura y de la investigación después de haber recibido el bautismo de su existencia en la sabia y vieja Europa» ${ }^{54}$.

En esta arista de la validación del espiritismo como ciencia, cabe una aclaración. Éste reclamaba para sí el lenguaje de la ciencia, pero no se reconocía en el grupo de aquellos «refinados materialistas» que renegaban de la palabra divina. Por el contrario, en el texto se retoma la idea bíblica de la Revelación para explicar el punto crucial del saber espiritista. Sólo por medio de la Revelación, que «ningún científico niega», avanza el género humano; mediante la «constante correspondencia de los seres vivientes con los que han alcanzado un grado de perfección en el mundo espiritual» Dicha conjunción de la ciencia con la fe, que da sustento al espiritismo, es descripta por Páez de la siguiente manera:

Estos hechos, que sin estar en la categoría de esos milagros portentosos que nos relata la historia bíblica de los tiempos antiguos, ellos se manifiestan a los ojos de la realidad y bajo tales circunstancias, dudar de ello es más que una preocupación, más que una torpeza de la imaginación, es una atentado brusco y desleal contra los adelantos de la civilización moderna, que día a día se encumbra sobre pedestales inconmovibles ${ }^{55}$.

La idea de dos mundos, el científico y el religioso, conectados por el saber espiritista, tiene su correlato en la noción de que el mundo material y el espiritual se vinculaban por la existencia de un fluido universal, «eléctrico», «electronervioso» o «periespíritu», que no era otra cosa que la sustancia que recorría el cuerpo de los seres vivos. Era lo que el magnetismo llamaba fluido magnético que, si se desestabilizaba, generaba la enfermedad. El método curativo de Quinteros, en esta tónica, consistía en la aplicación de pequeñas dosis de agua natural o magnetizada, en tanto «se basa en los principios del magnetismo animal uno de los cimientos del espiritismo, sistema que desarrollado y ejercitado en toda su amplitud, reúne esta condición ventajosa: que cuando no consigue dar la salud al enfermo no la empeora tampoco ni le causa mayor daño por muy grave que sea la dolencia. El agua magnetizada penetrando por todos los poros del cuerpo humano se dilata y se condensa de tal modo que opera en el organismo una transformación completa, y como

54 Atanacio Páez en representación de Don Juan P. Quinteros contra el Consejo de Higiene, 26 de octubre de 1887, AGPSF, Ministerio de Gobierno, Agricultura, Culto e Instrucción Pública, Sección Gobierno y Culto, expediente núm. 30, folio 33.

55 Idem. 
consecuencia de esta, ciertos fluidos impresionan y regeneran a ese elemento vital llamado sangre $»^{56}$.

La descripción de las técnicas hace que este documento permita un contraste con aquellos que son más frecuentes de encontrar a propósito de las prácticas rotuladas como curanderismo. Por lo general, contamos con las denuncias compungidas de médicos y farmacéuticos, realizadas incluso en momentos críticos como las coyunturas epidémicas de 1886 y 1887, donde el lenguaje para referirse a sanadores y curanderos era el primer marcador de su condición de amenaza para la población:

Habiendo tomado el curanderismo grandes proporciones con gran detrimento de la salud de este pueblo; (...) usan remedios heroicos en dosis crecidísimas y esponen de este modo la vida de los enfermos; (...) establecimientos llamados farmacias o botica espenden medicamentos peligrosos ${ }^{57}$.

Es por ello que la estrategia de un espiritista como Quinteros, como se vio, fue mostrar su desprecio hacia el lucro, llevando a cabo una práctica moderada e inocua, basada en «el elemento más básico para la vida: el agua», y por sobre todas las cosas, como defensor del progreso de la ciencia y la civilización. En adición a enumerar los fundamentos científicos del espiritismo, este efecto se logró por medio de la caracterización de sus detractores, y sus motivaciones. Porque si Quinteros era un inocuo y caritativo sanador, ¿qué clase de sentimientos e intereses podían sustentar su persecución y castigo? Páez lo puntualiza muy certeramente: «demasiada vanidad, propia de espíritus retrógrados y de la fuerza autoritaria que reniega muchas veces del progreso universal de las ideas» ${ }^{58}$.

\section{AlgunAS REFLEXIONES FINALES}

A finales del siglo XIX, se anunció en Argentina un proceso de medicalización que formó parte tanto de la formación del Estado como de la moder-

56 Atanacio Páez en representación de Don Juan P. Quinteros contra el Consejo de Higiene, 26 de octubre de 1887, AGPSF, Ministerio de Gobierno, Agricultura, Culto e Instrucción Pública, Sección Gobierno y Culto, expediente núm. 30, folio 44.

57 Guillermo Ovalle se presenta en queja contra los curanderos de Helvecia, 8 de octubre de 1894, AGPSF, Ministerio de Gobierno, Agricultura, Culto e Instrucción Pública, Sección Gobierno y Culto, expediente núm. 6, folio 7.

58 Atanacio Páez en representación de Don Juan P. Quinteros contra el Consejo de Higiene, 26 de octubre de 1887, AGPSF, Ministerio de Gobierno, Agricultura, Culto e Instrucción Pública, Sección Gobierno y Culto, expediente núm. 30, folio 47. 
nización social. Puede destacarse que la élite médica se consolidó como corporación por medio de la lucha con otros actores que también se ocupaban de la salud y a quienes los médicos, de la mano del Estado, fueron dejando fuera de la norma. El presente artículo analizó el caso del espiritista Juan P. Quinteros, multado y encarcelado por ejercicio ilegal de la medicina y tildado de curandero. Este caso permitió indagar en las políticas de «descalificación» del sentido que los actores daban a sus prácticas de cuidado de la salud que formaron parte del establecimiento de la hegemonía del discurso médico.

La construcción de algunos rasgos identitarios, reivindicatorios, subjetivos de la figura de Quinteros que el texto de Páez propone, siempre apelando a la voz del primero, reviste dos estrategias generales que se entrelazan y complementan. La primera de ellas, que podría considerarse negativa, consiste en establecer que Quinteros no es un curandero. Como se vio, ello se logra arriesgando una primera descripción de la práctica y métodos de Quinteros. Su práctica, a diferencia de la de los curanderos, no sólo es efectiva sino que está basada en la ciencia y no es en ninguna forma peligrosa para el enfermo. En coincidencia con el discurso médico y estatal, describe a los curanderos como estafadores y oportunistas, que se lucran con la salud de los pobres. Que Quinteros atienda a los dolientes de forma gratuita demuestra cómo, también en este aspecto, se diferencia de ellos. Finalmente, se destaca cómo el escrito pone en juego lo que llama la condición social del sanador. Quinteros se siente insultado al ser llamado curandero, porque comparte que éstos son de una moral dudosa, son holgazanes e ignorantes.

En segundo término, la forma en que Quinteros se define a través de su apoderado también es clara y explícita. Juan P. Quinteros es espiritista, por lo que en el plano moral comparte la misión de aliviar a los dolientes, y mueve su voluntad la inspiración divina, que no puede tener otro fin que hacer el bien desinteresadamente, razón por la cual no cobra por sus servicios y atiende al rico y al pobre por igual. Por otro lado, se sitúa al espiritismo del lado del progreso y la civilización, frente a sus detractores, los retrógrados y orgullosos. El espiritismo reivindica una relación estrecha entre la ciencia y la fe, y acusa, a quienes no pueden asumirla, de frenar el progreso de la humanidad. Ello se ve claramente cuando el texto retoma la idea bíblica de la Revelación para explicar el punto crucial del saber espiritista, a saber, una constante correspondencia de los seres vivientes y el mundo espiritual.

Más allá de los saberes sobre la salud que la presentación expone y las nociones estrechas de las que acusa a la corporación médica santafesina, lo antedicho supone la necesidad de revisar críticamente los discursos médicos sobre los otros curadores. Ello porque, en un discurso médico que los unifor- 
mó, se perdieron las singularidades positivas que los protagonistas construyeron y utilizaron para construir sus posiciones sociales concretas. A su vez, esto pone de relieve las tensiones y enfrentamientos que este proceso de legitimación y deslegitimación de saberes y prácticas supuso. El caso de Juan P. Quinteros ilustra precisamente esta cuestión: es un ejercicio de reafirmación, no sólo de los derechos que portaba como ciudadano, sino de una identidad que consideró tergiversada, por medio de multas y prisiones humillantes, pero también por medio de la imposición de una identidad, la de curandero, que él rechazaba.

Finalmente, resta anotar que la presentación destacó que son los testimonios de los vecinos la prueba última de la legitimidad de Quinteros, lo cual sugiere que, hacia finales de la década de 1880, el monopolio de las prácticas legítimas de curar no estaba sellado en favor de la medicina, y que las herramientas, estrategias y recursos de algunos de los sanadores heterogéneos que se constituyeron en objeto del ataque médico fueron múltiples y contaron con apoyos importantes.

\section{BIBLIOGRAFÍA}

Álvarez, Juan, Ensayos sobre la historia de Santa Fe, Buenos Aires, Malena, 1910.

Armus, Diego, La ciudad Impura, Buenos Aires, Edhasa, 2007.

Ayrolo, Valentina (comp.), Economía, Sociedad y Política en el Río de la Plata del Siglo XIX. Problemas y Debates, Rosario, Prohistoria Ediciones, 2010.

Belmartino, Susana, "Coyuntura Crítica y Cambio Institucional en Salud: Argentina en los Años 40", Salud colectiva, 3/2 (online, 2007): 177-202.

Bohoslavsky, Ernesto y Di Liscia, Silvia, "La profilaxis del viento. Instituciones represivas y sanitarias en la Patagonia argentina, 1880-1940", Asclepio. Revista de Historia de la Medicina y de la Ciencia, LX/2 (Madrid, 2008): 187-206.

Bonaudo, Marta (dir.), Liberalismo, Estado y orden burgués (1852-1880), Buenos Aires, Sudamericana, 2007.

Bonet Safont, Juan Marcos, "La imagen del magnetismo animal en la literatura de ficción: los casos de Poe, Doyle y Du Maurier", Dynamis, 34/2 (Granada, 2014): 403-423.

Bubello, Juan Pablo, Historia del esoterismo en la Argentina. Prácticas, representaciones y persecuciones de curanderos, espiritistas, astrólogos y otros esoteristas, Buenos Aires, Biblos, 2010. 
Carbonetti, Adrián, “La Construcción del poder médico en el marco de la formación del Estado Nacional y la reestructuración de los Estados Provinciales. El caso de Córdoba. 1869/1914", separata de las III Jornadas de Historia de Córdoba, Córdoba, Ed. Junta Provincial de Historia, 1997: 241-255.

Carbonetti, Adrián, "Cólera y conflicto en la ciudad de Córdoba", Boletín Mexicano de Filosofía e Historia de la Medicina, V/10-2 (México, 2007): 71-78.

Carbonetti, Adrián, "Los caminos del cólera en Argentina durante el siglo XIX", publicación electrónica, III Congreso de Alap, 2008.

Carbonetti, Adrián, Aizenberg, Lila y Rodríguez, María Laura, "La Historia Social de la Salud y la Enfermedad: conformación, logros y desafíos”, Revista Estudios, 30 (Córdoba, 2014): 145-157.

Carbonetti, Adrian y Drovetta, Raquel, "Curanderismo versus medicina académica a mediados del siglo XIX. Conflictos en torno a la 'práctica ilegal de la medicina' en la provincia de Santa Fe, Argentina en 1886/87', 53. ${ }^{\circ}$ Congreso Internacional de Americanistas, México DF, Universidad Iberoamericana de México, 2009: s/p.

Carrillo y Ancona, Crescencio, Verdadera filosofía del magnetismo animal y el espiritismo o El demonio considerado en sus relaciones con la humanidad, México, R. Pedrera, 1869.

Dahhur, Astrid, “Ataques a curanderos. La medicina y su lucha por el control social de la población en los primeros años del siglo XX", XIV Jornadas Interescuelas/ Departamentos de Historia, Mendoza, UNCuyo, 2013: 1-18.

Delrio, Walter Mario, Memorias de expropiación. Sometimiento e incorporación indígena en la Patagonia 1872-1943, Buenos Aires, Universidad Nacional de Quilmes, 2005.

Di Liscia, María Silvia, Saberes, terapias y prácticas médicas en Argentina (17501910), Madrid Consejo Superior de Investigaciones Científicas, 2002.

Di Liscia, María Silvia, Saberes, Terapias y Prácticas Médicas en Argentina (17501910), Madrid, Biblioteca de Historia de América/Consejo Superior de Investigaciones Científicas, 2003.

Di Liscia, María Silvia, "Reflexiones sobre la nueva historia social de la salud y la enfermedad en Argentina", Adrián Carbonetti, y Ricardo González Leandri (eds.), Historias de salud y enfermedad en América Latina, Siglos XIX y XX, Córdoba, Editorial CEA/CONICET, 2008: 15-47.

Edelman, Nicole, "Lo oculto y las terapéuticas espiritistas del espíritu y del cuerpo en Francia (1850-1914): de la creencia al saber y vuelta", Asclepio. Revista de Historia de la Medicina y de la Ciencia, LVIII/2 (Madrid, 2006): 39-62.

Faberman, Judith, Las Salamancas de Lorenza. Magia, Hechicería y curanderismo en el Tucumán colonial, Buenos Aires, Siglo XXI, 2005. 
Ferreira, Luis Otavio, "Medicina impopular. Ciencia médica e medicina popular nas páginas dos periódicos científicos (1830-1840)", Chaloub Sydney, Vera Regina Beltrao Márques, Gabreiela Dos Reis Sampaio y Carlos Roberto Galvao Sobrinho, Artes e oficios de curar no Brasil, Campinas, Editoria UNICAMP, 2003: 101-122.

Fleitas, Mirta, “¡Queremos un mano santa!: actores y significados de una revuelta acontecida en 1929 San Salvador de Jujuy", Salud Colectiva, 3 (Jujuy, 2007): 301-313.

Fradkin, Raúl y Garavaglia, Juan Carlos (coords.), La construcción nacional, Buenos Aires, Taurus, 2011. Colección Argentina, tomo II.

Galindier, Jaques, Lagarriaga, Isabel y Perrin, Michel (comps.), Chamanismo en Latinoamérica, una revisión conceptual, México, Plaza y Valdés Editores, 2001.

Gallo, Exequiel y Wilde, Josefa, "Un ciclo revolucionario en Santa Fe (1876-1878)", Revista Histórica, 1/7 (Buenos Aires, 1980): 161-203.

Garcés, Carlos, "Místicos, curanderos y hechiceros: Historias de afroamericanos en la sociedad del Tucumán colonial", Contra Relatos desde el Sur. Apuntes sobre Africa y Medio Oriente, V/7 (Córdoba, 2010): 9-26.

González De Pablo, Ángel, "Sobre los inicios del espiritismo en España: la epidemia psíquica de las mesas giratorias de 1853 en la prensa médica”, Asclepio. Revista de Historia de la Medicina y de la Ciencia, LVIII/2 (Madrid, 2006a): 63-96.

González de Pablo, Ángel, “Animal magnetism in Spanish medicine (1786-1860)”, History of Psychiatry, 17/3 (London, 2006b): 279-298.

González Leandri, Ricardo, Curar, persuadir, gobernar. La construcción histórica de la profesión médica en Buenos Aires, 1852-1886, Madrid, CSIC, 1999.

González Leandri, Ricardo, "La profesión médica en Buenos Aires 1852-1870", Mirta Lobato (dir.), El progreso, la modernización y sus límites (1880-1916), Buenos Aires, Sudamericana, 2000. Nueva Historia Argentina, tomo V.

González Leandri, Ricardo, "El Consejo Nacional de Higiene y la consolidación de una elite profesional al servicio del Estado. Argentina, 1880-1900”, Anuario de Estudios Americanos, 6 (Sevilla, 2004): 112-133.

González Leandri, Ricardo, "La consolidación de una inteligentzia médico profesional en Argentina: 1880-1900”, Diálogos. Revista Electrónica de Historia, 7 (Costa Rica, 2006): 36-79.

Graus, Andrea, “¿Dobles o espíritus? las teorías del desdoblamiento frente al espiritismo en la españa de principios del siglo XX", Asclepio. Revista de Historia de la Medicina y de la Ciencia, 66/1 (Madrid, 2014): 1-11.

Lobato, Mirta (ed.), Politica, médicos y enfermedades. Lecturas de la historia de la salud en la Argentina, Buenos Aires, Editorial Biblos, 1996. 
Mallimaci, Fortunato y Gimenez Beliveau, Verónica, “Creencias e increencia en el Cono Sur de América: Entre la religiosidad difusa, la pluralización del campo religioso y las relaciones con lo público y lo político", Revista Argentina de sociología, V5/9 (online, 2007): 44-63.

Molina, Ivan y Palmer, Steven, La voluntad radiante. Cultura impresa, imagen y medicina en Costa Rica (1897-1932), San José, Editorial Porvenir y Plumsock Mesoamerican Studies, 1996.

Montiel, Luis, "Síntomas de una época: magnetismo, histeria y espiritismo en la Alemania romántica", Asclepio. Revista de Historia de la Medicina y de la Ciencia, LVIII (Madrid, 2006): 11-38.

Montiel, Luis y González de Pablo, Ángel (coords.), En ningún lugar, en parte alguna. Estudios sobre la historia del magnetismo animal y del hipnotismo, Madrid, Frenia, 2003.

Müller Scafuto Scoton, Roberta, "Espiritismo e medicina no Brasil: um balanço historiográfico", Sérgio Ricardo da Mata, Helena Miranda Mollo e Flávia Florentino Varella (orgs.), Anais do 3. ${ }^{\circ}$ Seminário Nacional de História da Historiografia: aprender com a história?, Ouro Preto, Edufop, 2009: 61-72.

Nebreda, Jesús, "Sobre hechiceros y curanderos o El antropólogo y su estrategia", Gazeta de Antropología, 11 (Granada, 1995): 1-12.

Palmer, Steven, 'La 'voluntad radiante' del Profesor Carbell. Medicina popular y populismo médico en Costa Rica en el decenio de 1930”, Diego Armus, Entre médicos y curanderos. Cultura, historia y enfermedad en América latina moderna, Buenos Aires, Grupo Editorial Norma, 2002: 259-292.

Palmer, Steven, From popular medicine to medical populism: doctors, healers and public power in Costa Rica. 1800-1940, Durham, Carolina del Norte, Duke University Press, 2003.

Partenio, Florencia, "Rosario en cuarentena: normalización y disciplinamiento de la población durante las epidemias, 1860-1904", Urvio, Revista Latinoamericana de Seguridad Ciudadana, 7 (Quito, 2009): 83-97.

Pascual, Cecilia, "La epidemia de cólera como condensación de sentidos. Culturas urbanas, narraciones clínicas y políticas higiénicas en Rosario, 1886/7", Història Ciência Saùde, Río de Janeiro, Manguinhos, FIOCRUZ, 2015: 1077-1093.

Prieto, Agustina, Rosario. Epidemias, Higiene e higienistas en la segunda mitad del siglo XX. En Lobato, Mirta Zaida. Política, médicos y enfermedades, Mar del Plata, Biblos, 1997.

Quereilhac, Soledad, La imaginación científica Ciencias ocultas y literatura fantástica en el Buenos Aires de entresiglos (1875-1910), tesis para aspirar al grado de doctora en Historia, Serie de tesis del Instituto Ravignani, Buenos Aires, 2010. 
Ranisio, Gianfranca, "Madri, medici e curanderos una ricerca messicana sull' ideología della salute", La Ricerca folklórica, 25 (Roma, 1992): 133-135.

Reguera, Andrea (coord.), Los rostros de la modernidad. Vías de transición al capitalismo. Europa y América siglos XIX y XX, Rosario, Prohistoria, 2009.

Rodríguez, María Laura, Carbonetti, Adrián y Andreatta, María Marta, "Prácticas empíricas y medicina académica en Argentina. Aproximaciones para un análisis cuanticualitativo del Primer Censo Nacional (1869)", Revista Historia Crítica, Departamento de Historia, Facultad de Ciencias Sociales, 13 (Colombia, 2013): 81-108.

Santamaría, Daniel (comp.), Ocultismo y espiritismo en la Argentina, Buenos Aires, CEAL, 1992.

Teixeira Weber, Beatriz, As artes de curar. Medicina, Religião, Magia e Positivismo na República Rio-Grandense, 1889-1930, Santa Maria/Bauru, Ed. da UFSM/ EDUSC-Ed. da Universidade do Sagrado Coração, 1999.

Vallejo, Mauro Sebastián, “Alberto Díaz de la Quintana y las tensiones del campo médico en Buenos Aires (1889-1892). Hipnosis, curanderismo y médicos extranjeros en la Argentina finisecular", Revista Culturas Psi/Psy Cultures, 4 (Buenos Aires, 2015): 53-84.

Fecha de recepción: 27 de enero de 2016.

Fecha de aceptación: 3 de mayo de 2016.

\section{Juan P. Quinteros, spiritist. Disputes over the legitimate meanings of the art of healing in late nineteenth-century Santa Fe}

Towards the end of the nineteenth century, a process of medicalization began in Argentina as part of the process of state building and social modernization. Although local and regional realities show distinguishable characteristics, a common feature was that the consolidation of the medical elite as a corporation came about as the result of a struggle with other social actors who also looked after the health of the population. This article analyses the arguments put forward by the spiritist Juan Quinteros while facing persecution at the hands of the Hygiene Council, with the aim of identifying which characteristics of spiritism Quinteros made visible when defending his subjectivity and healing practice.

KeY WORDS: Santa Fe; social history of health; spiritism; nineteenth century. 